\title{
Hands-on history
}

\author{
By Margaret Schaus
}

Reference Librarian

Haverford College

\section{Working with historical documents and artifacts as an alternative to the library research paper.}

$t$ is difficult to choose an image that summons up the peculiar mixture of despair and restlessness, boredom and anxiety that so often characterizes the library research paper. Are students painfully, mindlessly toiling like Sisyphus, never quite to reach their goal, or are they blown aimlessly hither and yon from card catalog to stacks, caught like Paolo and Francesca in some bibliographic inferno? From the students' points of view, whatever literary image applies, the reality is all too hellish.

Meanwhile, faculty members and librarians cannot always play the faithful, wise Virgil for the questing student researcher. Sometimes the student does not ask for help; at other times the student has so little interest in the topic or assignment that the reference interview or term paper tutorial quickly turns into a librarianly monologue; at still other times the student does not understand the term paper topic or cannot explain it clearly to the librarian.

Then again, too often the research paper assignment is a decrepit old war horse that cannot hope to interest students let alone meet the classroom goals of increasing their knowledge and understanding, of developing their skills in evaluating and synthesizing information, constructing an argument, and writing clearly and gracefully. Nor can such an assignment hope to meet the library's goals of teaching research methods and promoting an understanding and mastery of a discipline's literature. And all too often between the Scylla of inexperience and the Charybdis of poorly planned assignments, students never get much further than boredom and anxiety.

It is not surprising that proponents of courseintegrated bibliographic instruction like Evan Farber of Earlham College advocate alternatives to the term paper, since at a fundamental level the type of class assignment dictates the material and style of library instruction. ${ }^{1}$ An equally important consideration is student interest and enthusiasm. Term paper alternatives that more closely approximate real academic scholarship or professional projects capture students' enthusiasm and challenge them with higher standards.

Two alternatives to the term paper assignment have been used at Haverford College for some years to help meet faculty and librarians' goals in both teaching research methods and increasing students' understanding and appreciation of history. The following descriptions may suggest an

${ }^{1}$ See, for example, Evan I. Farber, "Alternatives to the Term Paper," in Thomas G. Kirk, ed., Increasing the Teaching Role of Academic Libraries (San Francisco: Jossey-Bass, 1984), and Craig Gibson, "Alternatives to the Term Paper: An Aid to Critical Thinking," Reference Librarian 24 (1989): 297-309. 


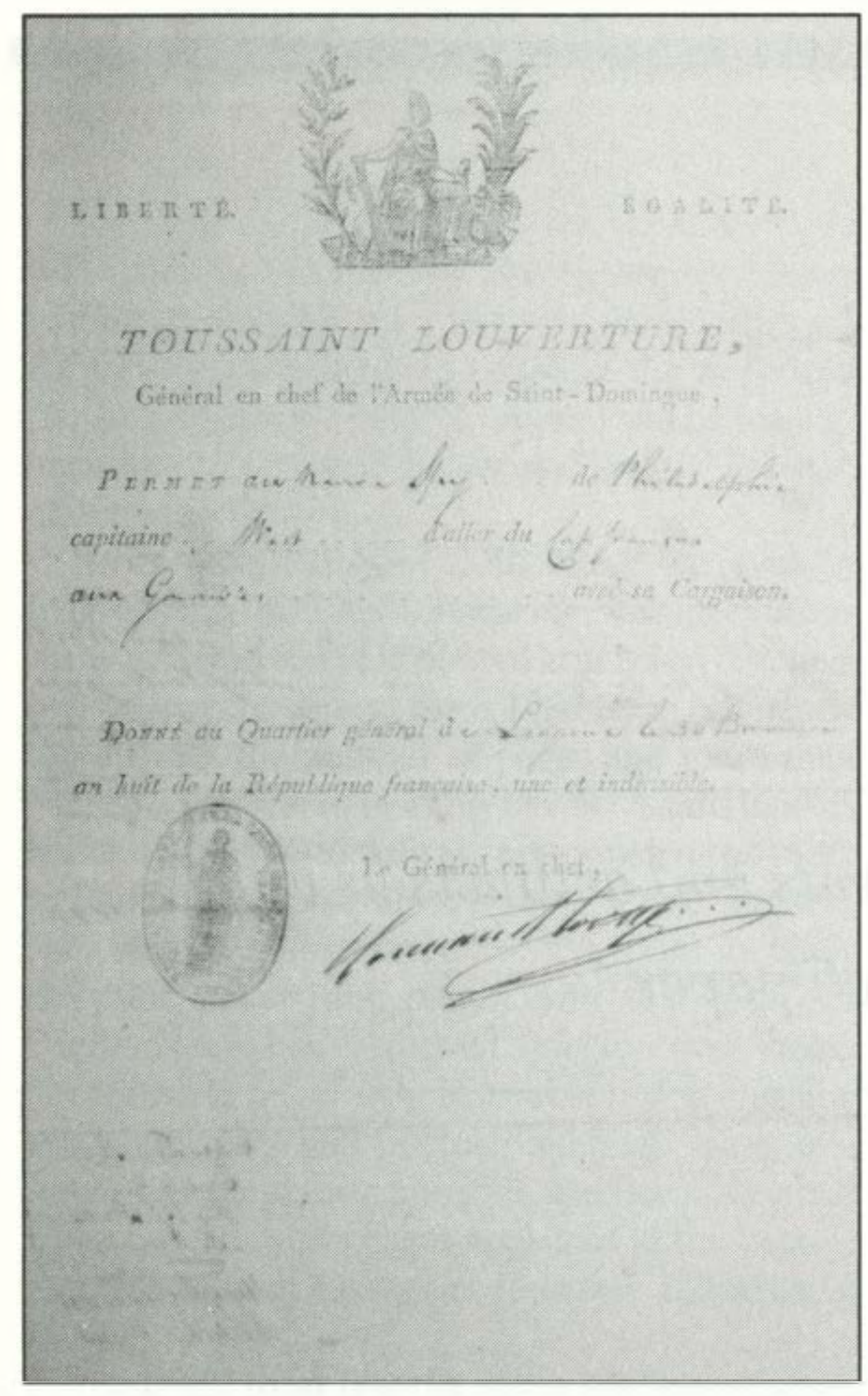

French passport signed by the Haitian revolutionary leader and former slave, François-

Dominique Toussaint l'Ouverture, on the thirtieth of Brumaire [November 28, 1799] for a merchant ship from Philadelphia. Courtesy of the Charles Roberts Autograph Letters Collection, Haverford College Library.

entire research project or a specific technique or approach that other colleges or universities may wish to incorporate into their curriculum and bibliographic instruction program.

Haverford College, founded by Quakers in 1833 , is a small liberal arts institution with high academic standards. The student body is less than 1,200 and the college places an emphasis on close faculty-student working relationships. History is one of the most popular majors, averaging 30 to 35 students per year. Every fall, junior history majors in the Seminar on Historical Evidence come to the reference desk with many detailed questions.

"Who was Mrs. H. Orr-Ewing and how did she know the Japanese crown prince Akihito?"

"Why would people have needed a darning egg with a tight-fitting metal ring?"

"Can I get copies of an abolitionist newspaper published in Kansas?"

"How can I find out about the introduction of Merino sheep into the United States?"
These questions arise because of two projects the students work on in the seminar: the first, the study of an artifact; the second, preparation of an edition of a document. These two projects for the Seminar on Historical Evidence date back to 1969. They resulted in part from a student revolt against traditional comprehensive exams as well as from the faculty's desire to bring students closer to the work that historians do.

The historical artifact assignment tries to get students to think about all the different types of evidence beyond the scholarly monograph and journal, even beyond the written word in any form. ${ }^{2}$ It is an exercise in deductive reasoning and detective work that often takes students from libraries to hardware stores, auto repair shops, and agricultural museums. In the document assignment the students transcribe a document from the library's special collections, explain the references to people, places, and events, and put the document within its wider political, social, and cultural contexts. $^{3}$

In that both assignments treat history as "present," as involving concrete objects and documents, not simply words in books, the seminar conveys the excitement of historical discovery in an immediate way. Furthermore, because the course has a widespread reputation for puzzling people to the point of distraction, students come partly eager to dazzle everyone with their deductive powers and partly apprehensive of complete and abysmal failure. Both assignments conclude with "show and tell" sessions in which students make brief presentations and are questioned by faculty about their research and the conclusions reached. Under these circumstances there are great opportunities for making a name for yourself in one fashion or another.

Until recently the library's only official part in the seminar was to host a "document evening" during which the students chose their texts and the librarians spoke briefly about the history of Haverford's special collections and about rare book room etiquette. Three years ago, however, two librarians trained in history joined the staff, and it was relatively easy to persuade the faculty of the need for library instruction in the Seminar on Historical Evidence. Since then the seminar has become a

${ }^{2}$ For the use of artifacts as a primary source for teaching history, see Susan K. Nichols, ed., Historians/Artifacts/Learners: Working Papers (Washington, D.C.: National Endowment for the Humanities, 1982). Available as ERIC document ED 216947.

${ }^{3}$ For a description of the document assignment prior to the addition of bibliographic instruction, see John M. McKenna, "Original Historical Manuscripts and the Undergraduate," AHA Newsletter 16, no.3 (1978): 6-7. 
cooperative venture; librarians and history faculty work together to introduce the uses of different kinds of historical evidence, to train students in techniques of investigation and research, and to encourage careful analysis and thoughtful interpretation of conditions in other times and places.

In the class library meetings, librarians emphasize planning research strategies and choosing the most helpful types of sources - not memorizing the names of reference titles or learning the inner workings of the LC call number system. Handouts summarize such mechanics of library use as finding periodicals and using interlibrary loan procedures. If the students do not know these basics already, they will quickly become second nature as research on their artifacts begins. The librarians' goals for the seminar are, of necessity, more numerous and far-reaching than they would be for the typical term paper assignment. Students need more than an introduction to the literature of just one discipline because they must work comfortably in various fields, use a wide range of reference sources, and go beyond the usual monographs and journals to such primary sources as patent records, letters, and eyewitness accounts, and to scholars, collectors, and other knowledgeable individuals. To accomplish all of these goals, students need a creative and flexible approach to research; they must think widely, not restricting themselves to one narrow line of reasoning, one subject approach, or one reference title. They must be willing to change directions and adjust their strategy if new evidence suggests a different interpretation or if promising leads appear in an unexpected place.

The artifact in the first exercise is generally a tool that is not immediately identifiable. A leather glove with peculiar-looking hooks is not an instrument of torture but a corn husker. One student who successfully identified the corn husker published an account of his research in Small Farmer's Journal describing how a conversation with some Amish farmers led to an online search for "corn husker?" and eventually wound up with 1920s issues of Wallace's Farmer. ${ }^{4}$ The object might be hard to identify because it is a specialized tool not in common use, like a web stretcher for upholsterers, a veterinarian's animal ear trimmers, or a queen bee trap. Other times it is outmoded, a wooden spigot for tapping barrels or a decorative gas burner, for instance. In still other cases the artifact comes from a non-Western culture such as a ushabti, an ancient Egyptian funerary figurine, and an elephant bell from India. The professor who has coordinated the seminar for many years collects new objects in antique and second-hand shops during his annual trips across the country. $\mathrm{He}$ also solicits contribu-

${ }^{4}$ Michael A. Sisk, "Corn Husking Culture," Small Farmer's Journal 12 (Fall 1988): 76-77.

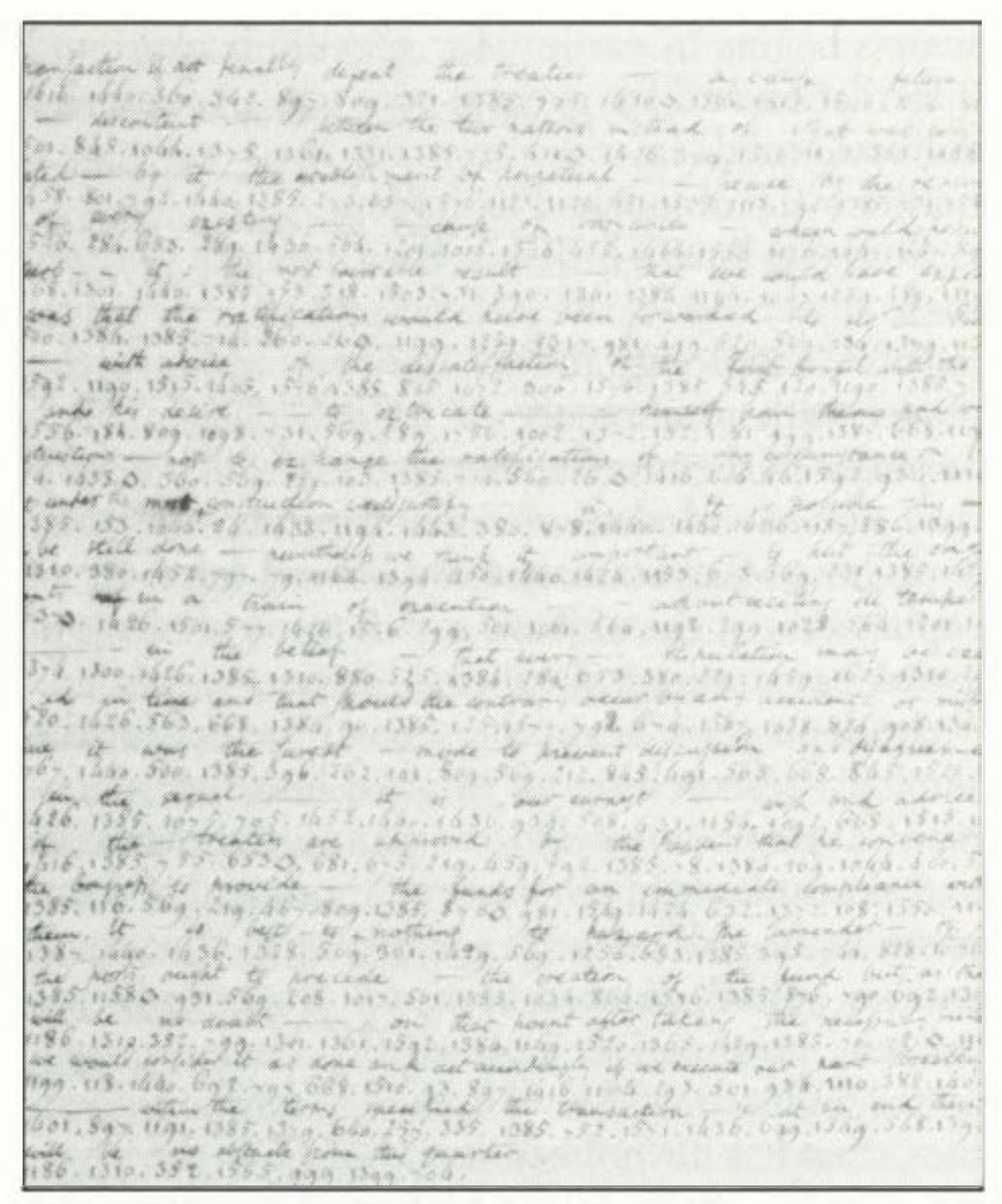

A page from a letter written partially in cipher in 1803 by Robert R. Livingston, U.S. Minister to

France. It was sent from Paris together with Napoleon's ratification of the Louisiana

Purchase. The code was translated and written above the numbers upon receipt in the U.S. Courtesy of the Roberts Collection.

tions and short-term loans from the college community; many faculty members bring artifacts back from research trips abroad.

Each student selects an object and is given the name of the donor. Students may ask donors questions about the provenance of the object, but donors can only confirm, not reveal, the identity of the object. By combining the physical evidence of shape, material, and markings with the information from the donor, the students have enough clues to go to the library for old tool and antique guides, trade catalogs, and special directories enabling them to contact museum curators, antique dealers, and skilled crafts people. But explanation, rather than identification, is the major goal of the report. The object reflects contemporary material conditions and social values and must be made to speak for the culture that fashioned and used it. What, for example, do whale bone stays from an 18th-century corset say about women's roles, health concerns, distinctions of social class, large-scale fishing, or the garment industry? A quick-release hub cap remover from the 1920s leads to questions about the growth of the automobile industry, the development of the highway system, and the greening of suburbia. Once students identify the artifacts, their 
search begins in earnest for specific background information and for general economic, social, and cultural trends in order to make the connections between the object and its milieu.

Students have a little less than a month to study their objects and write a three-part paper consisting of: 1) a thorough and accurate description of the object with a summary of its provenance; 2) a narrative of the investigative process which may or may not have led to an identification, including hypotheses that subsequently proved false; 3 ) an explanation of the object's significance in terms of social, economic, and cultural history.

Students then begin the second project for the seminar: research on an original historical document. It is not unusual to use manuscript materials to train students in scholarly methods and to demonstrate the gulf between a handwritten document and an edited, printed version. ${ }^{5}$ Haverford's approach, however, is noteworthy because each undergraduate works with an unpublished document that has never been used before in the seminar. For the students, the feeling of discovery and the sense of scholarly responsibility are both heightened because they are the only interpreters for these documents. Furthermore, their papers go on file in Special Collections along with the documents, thus becoming part of the scholarly record. Over the years more than a dozen students have published their papers in journals and books of collected essays. ${ }^{6}$

${ }^{5}$ Assignments using historical documents are discussed in Ross W. Beales Jr. and Randall K. Burkett, Historical Editing for Undergraduates (Worcester, Mass.: The authors, 1978); Sally Brett, "Shaping the User: An Academic Exercise," North Carolina Libraries 41 (Fall 1983): 139-40; Ernest Cassara, "The Student As Detective: An Undergraduate Exercise in Historiographical Research," History Teacher 14 (August 1985): 581-92; and J. Samuel Walker, "Teaching the Method of History: A Documentary Exercise," History Teacher 11 (August 1978): 471-82. On editing historical documents in general, see Mary-Jo Kline, A Guide to Documentary Editing (Baltimore, Md.: Johns Hopkins University, 1987), and Beth Luey and Kathleen Gorman, Editing Documents and Texts: An Annotated Bibliography (Madison, Wis.: Madison House, 1990).

${ }^{6}$ See, for example, Matthew Levinger, “'No Old Man's Sorrow': A New Ruskin Letter," Burlington Magazine 125 (March 1983): 158-59, and Paul M. Kelly, "Thomas Kelly Encounters Nazi Germany: His Letter from Strasbourg, 1938," in J. William Frost and John M. Moore, eds., Seeking the Light: Essays in Quaker History in Honor of Edwin B. Bronner (Wallingford, Pa.: Pendle Hill; Haverford, Pa.: Friends Historical Association, 1986), 183-208.
Every member of the history department chooses documents, usually letters, relating to his or her areas of interest, so that there is a wide choice of subject matter, geographic area, and time period. A student, for example, who has taken Asian history might work on a report from a Quaker mission in Japan, while someone interested in women's history could choose a letter from the artist Rosa Bonheur. Special efforts are made to find materials in foreign languages suited to students' abilities.

The seminar draws documents chiefly from two sources: the Quaker Collection and the Charles Roberts Autograph Collection. The Quaker Collection includes letters, journals, family papers, and Quaker documents from the 17th century onwards, such as an 1832 letter from Elizabeth Fry, known for her efforts at prison reform, or a 1797 document from ten native American women to a New York Quaker women's meeting. The Charles Roberts Autograph Collection, given by his widow to Haverford in 1902, originally consisted of over 12,000 autograph letters. It has grown in the intervening years to more than 20,000 items. The Roberts Collection ranges from the 16th century to the present and includes figures in every field of endeavor: Voltaire, Octavio Paz, Jenny Lind, Rubens, Margaret Sanger, Langston Hughes, Sally Ride, Linnaeus, and Cotton Mather. The documents sometimes include an interesting visual element, for example, a picture of a snipe in one of Audubon's letters and an elaborate seal on a letter from Thomas Jefferson to the first consul, Napoleon. Jefferson's letter concerns the diplomat Robert Livingston for whom there are a number of related documents in Haverford's collection, including coded letters that he sent to Washington in 1802 and 1803. Some letters are difficult to read because the writing is a challenge to decipher, others pose problems because they are so old that the spelling and grammar are unfamiliar. Not all the documents used are letters. Students have worked on wills, contracts, diaries, and even a 1799 safe conduct pass signed by the black revolutionary leader Toussaint l'Ouverture. Approximately ten manuscripts are purchased each year specifically for the Seminar on Historical Evidence. Purchases for the last few years include letters from Virginia Woolf to her nephew Quentin Bell, from Empress Marie Louise, and from the Duc de Rohan, a French military leader during the Thirty's Year's War.

All seminar students attend an evening session in the Special Collections wing of the library, where the history faculty briefly describe the documents that they have chosen. Students then each pick a document from a pool of around sixty choices. They will be given a photocopy of their document to take with them, but they must consult the origi- 
nal kept in Special Collections for evidence of watermarks and other physical conditions as well as for deciphering hard-to-read passages that may be clearer in the original than the photocopy. The students have six weeks to complete the project, that is, to prepare a critical edition consisting of an introduction, transcription, explanatory footnotes, and bibliography. The introduction must cover the document's provenance, its physical characteristics, biographical information about the writer, and a brief analysis of the document's historical significance. The document must be transcribed with the appropriate critical apparatus including a translation, if necessary. Footnotes should explain all references in the text that are not common knowledge, including passing remarks made about contemporary people, events, and issues. Footnotes should also comment on errors in the text and any other textual problems. In a few cases over the years students have proven documents to be copies rather than originals, and in one instance a Jonathan Swift letter was shown to be a forgery. The final part, the bibliography, may be done in the standard manner, or as an annotated bibliography or bibliographical essay.

While the librarians' long-term goals for the seminar include a familiarity with varied types of reference sources, an understanding of the structure of knowledge within academic fields, and the initiative to develop and modify a research strategy, the initial bibliographic instruction session only sets the stage for a semester-long consultation and learning process. ${ }^{7}$ During an initial 90 -minute session, two reference librarians alternate questions and answers with short presentations to get students thinking about ways to investigate their historical artifacts. They ask the students to analyze problems and to suggest possible solutions; in this way the librarians build toward a research strategy and a typology of reference sources. They discuss the importance of evaluating sources in terms of authority, viewpoint, purpose, and point in time. Examples drawn from previous seminars' experiences contrast secondary with primary sources and contemporary material with retrospective analysis. For example, a recent monograph describing 18thcentury papermaking in a certain sense gives a flat,

${ }^{7}$ Bibliographic instruction receives little or no consideration in the discussions of historical document assignments. One exception is by Agnes Haigh Widder and John Coogan, "Who Was Berut? Using Correspondence between World Statesmen in Bibliographic Instruction," Research Strategies 5 (Summer 1987): 135-38. For a more general discussion of library instruction in the use of primary sources, see Marilyn Lutzker, Research Projects for College Students: What to Write across the Curriculum (New York: Greenwood Press, 1988). one-dimensional kind of information. In contrast, the corresponding article in Diderot's Encyclopédie conveys layers of assumptions, values, and symbols suggesting the complex and sometimes untidy connections between technology and society. Librarians ask the students for examples of primary sources relating to artifacts, such as patents, manufacturers' catalogs, letters, and 19thcentury newspapers and magazines and then pass examples around for examination.

Because the students are about to begin investigating their artifacts, the librarians also discuss some very practical research shortcuts: annotated bibliographies, indexes, especially those that cover a very large number of sources like Bio-base, research guides, online computer searches, specialized research collections, and personal contacts with individual experts. The students receive two bibliographies, one on historical artifacts, material culture, and the history of technology; the other, longer one on reference sources for history, including biography, geography, statistics, government documents, directories and collection guides, and periodical and newspaper indexes. ${ }^{8}$ The bibliographies go beyond annotated lists of tools to include explanations of research strategy on such topics as patents, product advertisements, company information, and biographical sources for lesser known people. The bibliography on artifacts includes addresses, hours, and brief descriptions of a few regional museums and libraries with even a map for one institution that specializes in the history of technology. Handouts illustrate online searches, compare contemporary and retrospective sources of information, and show how to get the most from biographical indexes, subject encyclopedias, and newspaper indexes.

The librarians meet with the seminar students a second time when the class chooses among the unpublished documents. At this session a special collections librarian explains the etiquette for using manuscript materials, the library bookbinder talks about papermaking and watermarks, the Quaker bibliographer highlights the indexes and primary sources in the Quaker Collection, and the reference librarian describes the various types of reference tools that may help in transcribing and under-

${ }^{8}$ The two bibliographies, entitled "Selected Reference Sources in History for the Seminar on Historical Evidence" and "Selected Sources on Artifacts and Material Culture for History 361A," are available for loan from the LOEX Clearinghouse. You may also ask LOEX for the 14-page handout illustrating search strategies as well as the four short source lists dealing with document editing, identifying paper, watermarks, and inks, indexes, and primary sources in the Quaker Collection, and manuscript repositories. 
standing the historical documents. Again the students receive lists of sources in conjunction with the presentations.

Beyond these two group sessions, librarians encourage seminar members, as they do all other students, to stop at the reference desk or make appointments for individual research consultations. While students are working on their projects, long, close collaborations develop in some cases between librarians and students, and all the librarians at the reference desk are called on to help puzzle out clues as to the manufacturer of a surgical instrument or make their best guess at deciphering a quasi-legible word or passage in a 19th-century letter. Among the staff, the students quickly acquire metonymic monikers based on their projects like the "turnbuckle woman" and "Mr. Henry Clay." In addition to casual encounters at the reference desk, librarians encourage students to use the research advisory service. The student makes an appointment with the appropriate subject specialist in advance, so that the librarian can do preliminary checking or think of several directions out of the student's current dead end. Rather than settling for a hasty huddle at the reference desk, the librarian sets aside a block of time for the meeting, so that he or she can work with the student, outline possible research plans, and help with any parts that might be particularly troublesome. Since they meet in a relaxed, private setting, the student feels more comfortable bringing up additional problems or other aspects of the topic.

Because the bibliographic instruction component of the seminar has been in place for only three years, reference librarians are still working out ways to evaluate the results. The first year students answered a seventeen-item questionnaire that asked for an evaluation of various library resources and services and for suggestions in improving the reference collection and the bibliographic instruction for the seminar. Responses were overwhelmingly positive. The research consultation service and the bibliographic instruction presentations rated the highest. Several students pointed out specific subject areas that were poorly covered in the library's collections; we subsequently added needed materials particularly in the areas of material culture and the history of technology.

Instead of a questionnaire this past year, a reference librarian interviewed ten students, eight who had done honors quality papers and two others who, in the judgment of the history faculty, had not worked up to capacity. Most of the questions focused on how much they had learned about research. An open-ended request for suggestions concluded each session. In general, the students had dealt with a wide variety of sources in several different types of libraries and had developed conscious research strategies. The two students who had not worked up to capacity had a more difficult time conceptualizing the research experience, but both felt that they had wasted their efforts in finding and reading materials that were too general or focused on side issues. The interviews produced a number of suggestions ranging from heartfelt endorsements of old reference titles, found in obscure corners of the library, to the idea of a quick checklist for students to review their coverage of major research sources.

In addition to soliciting evaluations and information from the students directly, librarians read the artifact and document papers. They look for use of primary sources throughout and for identifications that go beyond the bare facts to analyze and interpret. In the bibliographies they look for overall numbers of sources, types of sources including journal articles, essays, dissertations, reference books, and manuscripts, and the scholarly quality of the sources. They check in particular the ones judged outstanding by the faculty.

Another form of evaluation for the library instruction program is the attitude of the History Department. The history faculty values the librarians' expertise and sees bibliographic instruction as an integral part of the seminar. This attitude is evident in everything from the collegial atmosphere in the seminar to the way bibliographic instruction is described in the syllabus. Confirmation of the faculty's commitment to course-integrated library learning came last year when the faculty voted to double the seminar's course credits primarily because of the new instruction in research and the resulting increase in student use of the library.

Paradoxically, student enthusiasm for research causes most of the seminar's problems. Some students don't know when to stop investigating and begin analyzing and writing, particularly with artifacts they cannot identify conclusively. Reminders in seminar and in individual conferences of the ultimate importance of explanation over identification help move students along. Furthermore, students sometimes have difficulty using research libraries and other special collections. The bibliographic instruction sessions address this problem by highlighting the requisite etiquette for using special collections, by giving referrals to a specific person within a library whenever possible, and by emphasizing the importance of preparing before a visit to a library, historical society, or museum.

The success of bibliographic instruction also created some problems in the first year. The library had not fully anticipated the seminar's impact on public services. Traffic at the reference desk increased, the number of interlibrary loan requests grew, especially for harder-to-locate materials like manufacturers' trade catalogs and 19th-century newspapers on microfilm, and gaps in the collec- 
tion, particularly in the area of material culture, were revealed. In subsequent years, librarians have regularly added titles to the collection specifically for the Seminar on Historical Evidence. Interlibrary loan procedures have been changed to redistribute the workload, and all bibliographic instruction sessions include an exhortation to the library faithful to use interlibrary loan as early as possible. Librarians also mention the research consultation service during instruction sessions. Its growing popularity takes some pressure off the reference desk.

Librarians and faculty members that may be interested in trying either of these projects will need to ensure that they have an adequate supply of artifacts or documents. At Haverford, the artifacts are re-used every four years with an entirely new group of students, but only unpublished documents are studied. Each is used only once, since the experience of historical discovery is paramount. If a college does not have enough suitable materials available in special collections, librarians and faculty could check the college archives for correspondence, minutes, and reports. The local historical society, museum, or public library may have pioneer diaries, early business records, and other historical materials that would supply many documents for research. The advantage in working with local documents is that the reference materials needed, including monographs, old newspapers, records, and knowledgeable individuals, are usually available in the immediate area. The research and writing that students do will be of benefit to the local museum and historical society, particularly for those organizations that do not have the staff or resources to investigate the manuscripts in their own collections.

All the participants in the Seminar on Historical Evidence at Haverford College profit from the experience. Students gain self-confidence in their skills as researchers and editors and in their abilities as scholarly analysts of evidence about conditions in other times and places. Faculty members teach historical methodology in an exciting and immediate fashion and receive better researched, more carefully reasoned project papers. Librarians train students in investigation and evaluation using a dynamic, interactive approach of problem analysis and research strategies. In so doing librarians establish a track record of effectiveness and dependability. By building up working relationships with both students and faculty, they promote bibliographic instruction throughout the campus. The final image of the student researcher then is not of the aimlessly wandering Paolo and Francesca, but of Dante under Virgil's guidance, journeying through a dark wood to a place of light, while learning much along the way.

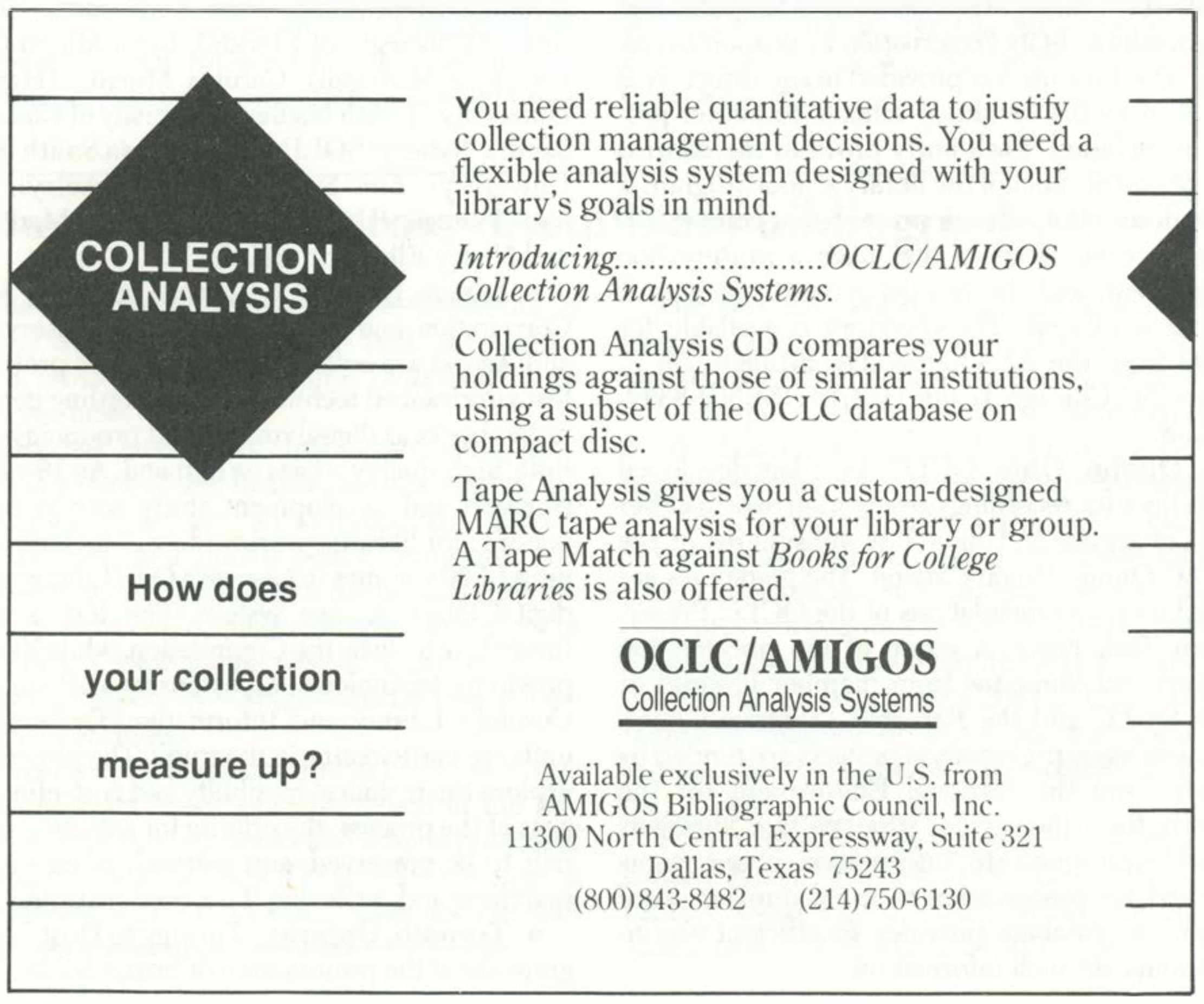

